\title{
Electronic Performance Support Systems: An Assistive Technology Tool for Secondary Students with Mild Disabilities
}

\author{
Katherine Mitchem \\ California University of Pennsylvania \\ Jason Kight \\ California University of Pennsylvania \\ Gail Fitzgerald \\ University of Missouri-Columbia \\ Kevin Koury \\ California University of Pennsylvania \\ Thitinun Boonseng \\ University of Missouri-Columbia
}

\begin{abstract}
This article presents the results of a qualitative study investigating the usability and perceived effectiveness of Strategy Tools ${ }^{\mathrm{TM}}$, an electronic performance system support designed for secondary students with mild disabilities to use independently in classroom and home situations. The StrategyTools software contains 39 computerized research-based strategy tools to support learning, behavior, and transition in high school and beyond. Two special education teachers each used the software with their high school students for one semester. Interviews were subsequently conducted with the two teachers and four students with behavior disorders who used the software. Interview responses were analyzed inductively for themes related to benefits, concerns, and usability. Design features of the software, the systems to support use of the software, and results of the qualitative analysis are reported. Recommendations for future research and suggestions for use of the StrategyTools software and support system are provided.
\end{abstract}

$\mathbf{T}$ There is clear evidence that program development and services for students with learning disabilities (LD) and/or emotional and behavioral disorders (EBD) are a high priority at the national level (Elam, Rose, \& Gallup, 1998; Kay, 1999). The No Child Left Behind Act (NCLB) (2001) and the Individuals with Disabilities Education Improvement Act (IDEA) (2004) each include several key components that set current priorities for the field. Specifically, the accountability provisions specified in NCLB and reiterated in IDEA provide a goal for all students to make adequate yearly progress toward curriculum/IEP goals to best prepare them for the 21st century. Further, IDEA 2004 maintains provisions for students to access the general education curriculum with highly qualified teachers, by providing appropriate and effective strategies and methods for student success, and to utilize positive behavioral supports to assist children in adapting to educational environments (U.S. Department of Education, 2004). 
Students with LD and EBD show some similarities in their learning and behavioral deficiencies (Swanson, 1988; Swanson \& Hoskyn, 1998). When involved in academic tasks, these students tend to use simpler, less effective strategies than average achievers and often fail to execute strategies correctly. Research is encouraging, however, as findings show that students with LD and EBD are capable of learning to act appropriately and that their conduct in school and work habits can improve with proper instructional and behavioral support (Lewis \& Doorlag, 2003; Reid, 1996). Self-regulation plays an important role in strategic performance, and research demonstrates positive effects on new learning as well as mastery and generalization (Reid, 1996).

Over the last decade, interest in and exploration of computers and related technologies have increased for educating children for the 21 st century. Early efforts in special education technology focused on applications for students with mild disabilities who might benefit from effective software design and for students with physical and sensory disabilities who needed adaptive devices and assistive technology for learning (Blackhurst, 1997; Fitzgerald \& Koury, 2006). Later efforts shifted to exploring effective instructional technologies to maximize learning and to support students with mild disabilities in the general education environment (Fitzgerald \& Koury, 2006; Woodward \& Rieth, 1997).

Throughout the history of special education technology, there has been little consideration, exploration, or research conducted on the uses of technologies to assist students with EBD. Little attention has been focused on the unique needs of this population or on any special applications that go beyond instructional programming for individuals with mild disabilities (Fitzgerald, 2005).

Assistive technology enables children with disabilities to participate more fully in all aspects of life (home, school, and community) and helps them access their right to a "free, appropriate, public education" in the "least restrictive environment." An assistive technology device is defined as "Any item, piece of equipment or product system, whether acquired commercially off the shelf, modified, or customized, that is used to increase, maintain, or improve the functional capabilities of a child with a disability" (IDEA, 1990). As such, appropriately designed and selected assistive technologies may provide supports for students with learning and behavior problems to ac- quire and practice the self-management, self-regulation, and self-advocacy skills that help them obtain optimal benefit from the general education curriculum.

Computer-based training and support mechanisms are an innovative approach to helping children gain control over personal behaviors. Although there are limited data on the use of computer-based instruction to support behavior change, research results are promising. For example, Fitzgerald and Werner (1996) reported success with a computerized verbal mediation essay as a cognitive retraining procedure to assist a student with significant behavioral disorders in changing his behavior. In this case study utilizing an $\mathrm{ABC}$ single-subject design, the computerized essay provided consistent practice and focused the child's attention and thoughts on behavioral choices and consequences. In another case study, the same researchers used a procedure in which software templates were developed for a student to create self-monitoring materials (Fitzgerald \& Werner, 1996).

In a recent study with high school students, Hartley (2001) found that although students could learn strategies from hypermedia computer programs, their learning did not impact performance. Hartley hypothesized that better outcomes might be achieved if instruction in learning strategies was integrated with opportunities to utilize the strategies in realistic settings. He concluded that with secondary students, their use of strategies ultimately depends on their decision to use a strategy, and lends support to the electronic performance support system (EPSS) approach by making the learner responsible and in charge of his/her own learning and performance as appropriate for secondary students.

Hypermedia (a nonlinear, learner-control type of software) offers benefits of personalizing instruction and encouraging strategic learning (Hartley, 2001). While there were early concerns about navigation difficulties related to hypermedia, research findings indicate that in well-designed hypermedia programs, experience has little impact (Fitzgerald \& Semrau, 1998) and the menu format is the best for all levels of learners in terms of achievement and attitudes (Farrell \& Moore, 2000). An appropriately designed cognitive tool extends the user's abilities to think and problem solve without increasing his/her cognitive load to figure out the appropriate process (Brown, Hedberg, \& Harper, 1994). Recent federally funded projects where students with learning disabilities utilize the 
computer as a study tool (electronic studying, electronic note-taking, learning study strategies) have concluded that technology tools provide bridges to support students in learning (not remediation) and that the technology works because it provides direct instruction as well as scaffolding to support learning (Anderson-Inman \& Horney, 1997; Anderson-Inman, Knox-Quinn, \& Szymanski, 1999; Lewis, 2005). These authors describe the computer as a cognitive tool for implementing computer-based study strategies but caution that technology is only successful when students assume responsibility for their own learning.

\section{The KidTools Support System}

The KidTools Support System ${ }^{\mathrm{TM}}$ (KTSS) is an EPSS that directly targets the use of behavior and academic performance support for students who have learning and/or behavior problems. Electronic performance systems offer tremendous potential for addressing the problems of youth for self-regulation, strategic learning, and self-determination. EPSS is one way to provide training and assistance by embedding help options, training, and online technical services into actual computer programs so that training is provided in the "right place, right time, right form" (Gustafson, 2000; Laffey, 1995). Thus, the goal of EPSS software is to provide whatever is necessary to ensure performance and learning at the moment of need in a seamless activity. This contrasts to older approaches where training and application were seen as sequential, separate efforts (Gery, 1991). Electronic performance support systems are starting to emerge in special education to provide real-time supports within learning contexts. EPSS can provide support at the point of need and adapt to learner differences and needs (Schaff, BannanRitland, Behrmann, \& Ok, 2005).

One group of tools to build self-regulation and use of problem solving in students with mild EBD and/or LD is KidTools ${ }^{\mathrm{rm}}$ (Fitzgerald \& Semrau, 1999). A similar program, called KidSkills ${ }^{\mathrm{TM}}$, was subsequently developed to provide a system of organization tools and learning strategy tools (Fitzgerald \& Koury, 2001-2002). Secondary students, teachers, and special educators who reviewed and tried out KidTools and KidSkills validated the EPSS approach and functionality of the tools for this age group, but requested more suitable graphics for more mature students and more advanced editing features, options for expanding the fields, and more complex content. Thus, a new version of the KTSS software, called StrategyTools, was prepared under a Steppingstones Technology in Innovation grant (Fitzgerald \& Koury, 2004-2005).

The StrategyTools software includes research-based strategies and provides easy-to-use template tools that can be personalized by students, teachers, and parents for school or home settings. It incorporates more mature formats (i.e., editing, linking, expanding, and content entry) suitable for older students compared to KidTools and KidSkills for elementary and middle school students. Special features that distinguish StrategyTools from the other tool programs include the following capabilities designed for supporting independent use:

1. Quick View section with thumbnails of all tools for easy selection.

2. Database support to store all previously made tools for easy revision.

3. Ease of editing content in the tool templates.

4. Report-looking print-outs of tools for use (not juvenile screen dumps).

5. Strategy Coach ${ }^{\mathrm{TM}}$ web site with practice scenarios and tool tips written for secondary students and interviews with students who used the tools.

The research-base for each tool strategy is presented in StrategyTool Resources ${ }^{\mathrm{TM}}$ - the teacher support informationbase that accompanies the StrategyTools software. Another support program is the Records Viewer program. With it, appropriate adults (e.g., teachers, parents) can search and view student records of tools that are stored on computers by entering a password, thus ensuring confidentiality of student records on public computers.

Investigations of implementation of the KidTools and KidSkills software for younger students reported improvements in both behavior and academic performance for students who used the software in resource room and inclusive schooling settings (Fitzgerald, Lynch, Semrau, \& Peng, 2000; Miller, Mitchem, Fitzgerald, Koury, \& Hollingsead, 2004; Miller, Koury, Mitchem, Fitzgerald, \& Hollingsead, 2005). In light of the limited research into the use of EPSS as an assistive technology approach for high school students with EBD, the purpose of this 
study was to investigate teachers' and students' perceptions of the usability and effectiveness of StrategyTools when used in a high school setting with students with emotional and behavioral disorders.

Strategy Tools contains 39 tools organized into six categories. The software was created using Adobe Authorware, thus allowing students to save their tool content on their personal file space. The software uses a school building as a metaphor and the theme-related tools can be found within various rooms in the building. The design of the metaphor was created in a 3-D authoring environment and rendered with bright colors to appeal to secondaryage students. A non-gender graphical figure named Tran serves as a coach by providing students directions and tips throughout the program (see Figure 1). Each tool creates a tool that can be printed for use. Table 1 displays the organizational structure of the software with a list of the tools found in each room.

Two of the tools used in this study are the Commitment Card and the Self-Awareness Tool. Figure 2 displays the Commitment Card that students can use to identify their goals and to monitor accomplishment of those goals. Figure 3 displays the Self-Awareness Tool that students can use to prepare for their IEP meetings. The contents focus on educational strengths and needs, functional skills, and transition planning skills for community living and work. The tools can be used for self-assessment as well as a discussion guide during the IEP meeting.

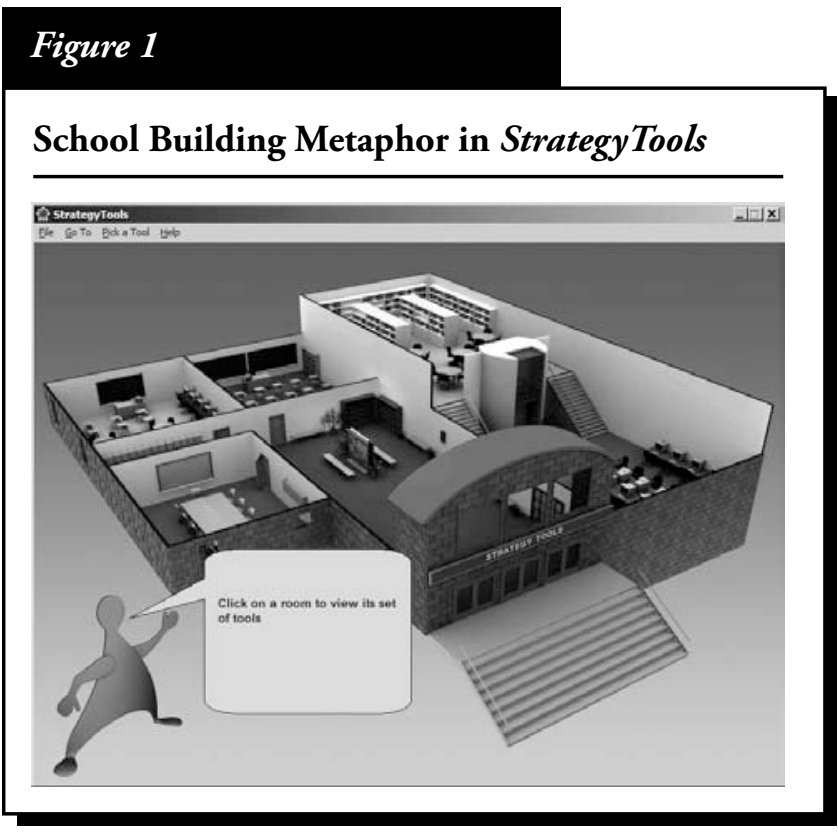

The conceptual framework of Strategy Tools is based on the innovative use of an EPSS to assist secondary students with LD and/or EBD by developing self-regulation, learning strategies, and transition planning skills using cognitive-behavioral approaches. The primary components are illustrated in Figure 4. Recognizing the importance of ecological variables surrounding an innovation, the framework addresses multiple systems that impact the innovation and support transfer and continued usage across settings, including parents and educators (Biemiller \& Meichenbaum, 1998; Butler, 1995; Luca \& Oliver, 2001). Because interactive, complementary processes occur when a specific innovation is nested within an ecology, interventions in the ecology will improve the adoption of the innovation (Peled, Peled, \& Alexander, 1994).

In addition to the content, materials, and methods that are incorporated in the EPSS software, implementation supports are provided in a complete system. Parent and teacher supports are located on the KidTools web site: http://kidtools.missouri.edu. These include two orientation/training modules with demonstration videos, practice activities, and the archives of an online discussion held in 2000 with teacher educators, the developers, and graduate students/practicing teachers. Supports for students to independently learn about the tools are provided as Strategy Coach on the StrategyTools web site: http://strategytools.org. This site includes descriptions and tips for using the tools, a simplified explanation of the EPSS approach, scenarios for interactive practice with feedback, and interviews with students who have used StrategyTools. Finally, to provide information on the tools, examples of completed tools, and tips for success, the StrategyTools Resources software program is provided on the CD and as a download from the StrategyTools web site.

\section{Method}

\section{Participants}

Participants in this study included four male high school students and two teachers, one of them acting as teacher-researcher. Students were three 9th-graders identified with a behavior disorder and one 11th-grader identified with Asperger Syndrome. All four students attended a study skills class every other morning (the high school 


\section{Table 1}

\section{Listing of Tools in StrategyTools}

\begin{tabular}{|c|c|c|c|}
\hline Location & Tool Category & Tools & \\
\hline Library & Getting Organized & $\begin{array}{l}\text { Assignment Card* } \\
\text { To Do List* }\end{array}$ & $\begin{array}{l}\text { Weekly Planner* } \\
\text { Job Aid }\end{array}$ \\
\hline Study Hall & Learning New Information & $\begin{array}{l}\text { Vocabulary Card* } \\
\text { Notetaking Tool* } \\
\text { Overview Tool }\end{array}$ & $\begin{array}{l}\text { Chunker } \\
\text { Compare/Contrastor* } \\
\text { KWHL Card* }\end{array}$ \\
\hline Classroom & Demonstrating Learning & $\begin{array}{l}\text { Essay Composer } \\
\text { Flashcards } \\
\text { Memory Card } \\
\text { Study Guide* }\end{array}$ & $\begin{array}{l}\text { Test Yourself } \\
\text { Planning a Report* } \\
\text { Project Review Card } \\
\text { Rubric Tool }\end{array}$ \\
\hline Computer Lab & Working on Projects & $\begin{array}{l}\text { Big Picture Card* } \\
\text { Getting Information } \\
\text { Source Scanner } \\
\text { Planning a Report* }\end{array}$ & $\begin{array}{l}\text { Project Map } \\
\text { Project Note Card } \\
\text { Project Review Card } \\
\text { Rubric Tool }\end{array}$ \\
\hline Conference Room & Solving Personal Problems & $\begin{array}{l}\text { Solving Problems* } \\
\text { Commitment Card* } \\
\text { Coping Tool } \\
\text { Making Choices* }\end{array}$ & $\begin{array}{l}\text { Monitoring Card* } \\
\text { STAR Card } \\
\text { Self-Contract } \\
\text { Two-Party Contract* }\end{array}$ \\
\hline Information Center & Moving into the Future & $\begin{array}{l}\text { Self-Awareness Tool* } \\
\text { Action Planner* } \\
\text { Transition Tool* } \\
\text { Job Search }\end{array}$ & $\begin{array}{l}\text { Education Search } \\
\text { Finding Services } \\
\text { Budgeting Tool } \\
\text { Activity Log/Plan }\end{array}$ \\
\hline
\end{tabular}

*Denotes tools used in this study

was on a block schedule) with the special education (behavior disorders) teacher who was the teacher-researcher (see Table 2 for information on demographics and students' behavioral concerns). The teacher-researcher was a male with seven year's teaching experience, who was also a doctoral student in special education at a local university. He received guidance in implementing StrategyTools through his doctoral seminar. The second teacher was a first-year female special education teacher, who implemented StrategyTools with her class of four high school students with learning disabilities; she did not receive support from the researchers but when she had questions about the software she consulted with the teacher-researcher who taught in the same building.

Data were collected from the teacher-researcher, his four students described above, and the first-year teacher. Data for the students with learning disabilities in the second classroom was not adequate for analysis; only the teacher feedback was included in the qualitative analysis.

\section{Setting}

The setting was the teacher-researcher's self-contained study skills class for students with behavior disorders at a medium-sized high school located in a northern West Virginia town. A second teacher in the building tried out the software with her students in a learning strategies class and provided feedback on the software and her implementation. 


\section{Figure 2}

\section{Commitment Card in StrategyTools}



\section{Implementation Procedures}

Tool introduction and use. The teacher-researcher used the software one to two times a week for 10 weeks. The students were given approximately 45 minutes to explore the software and become familiar with navigating the program using the school building as a metaphor before they were asked to create and implement tool strategies. The tools used by the four students during the intervention, are marked by an asterisk in Table 1. Tools were implemented from all six categories, thus providing a comprehensive test for the software by students in a real setting.
Intervention started in the study skills class following the exploration phase. The students first made tools that were relatively simple to allow them to "get their feet wet" and build behavior momentum and success using the software. After the students expressed that they were comfortable exploring the different rooms and tools in the software, the instructor introduced the Assignment Card in the library (category Getting Organized) as the first tool, using a guided instruction approach in which the instructor first modeled and then had each student fill in the tool. As there was only one computer in the classroom, students took turns constructing their own tool, while the rest of the class worked with the teacher 


\section{Figure 3}

\section{Self-Awareness Card in StrategyTools}

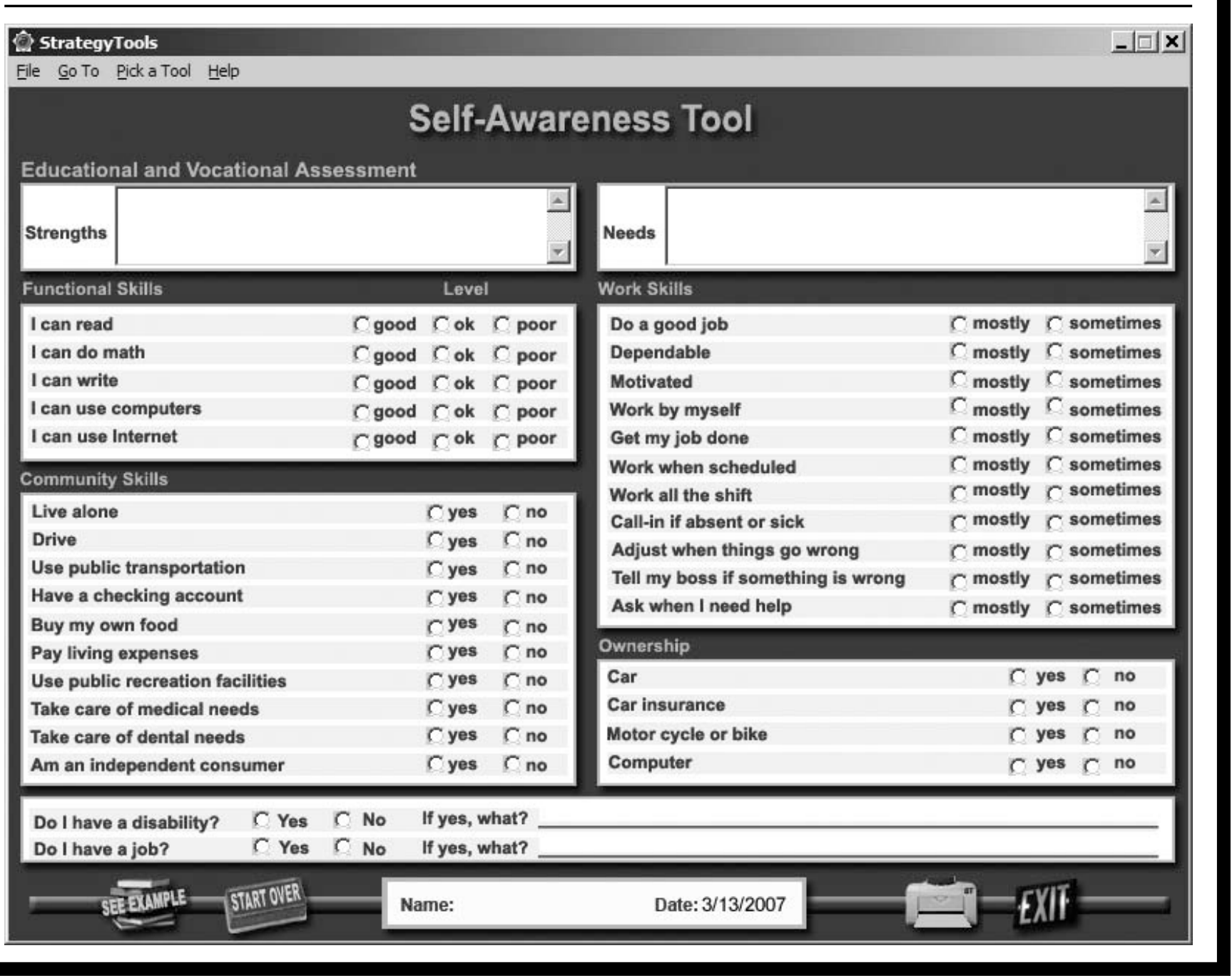

on a social skills lesson that correlated with the tool being constructed. Students also completed the To Do List and Weekly Planner tool in this introductory phase. All four students had started the year with a planner that would have served all of those functions, but at some point during the year, they had lost their planners and the instructor felt that organization skills were needed. Each lesson on the particular tool ranged from 15-30 minutes.

Given the students' individual needs, the next room that the students entered was the Conference Room, where they reviewed the tools under the category Solving Personal Problems. Each student developed a Commitment
Card to define and monitor target behaviors taken from their IEP objectives as well as for teachers to check off whether they agreed or disagreed that the commitment was fulfilled. The instructor noted that students had used check sheets in the past to serve this purpose, and were very self-conscious when they presented them to their teachers at the end of class periods.

As their annual IEP reviews and scheduling for courses approached in the spring, students utilized tools in the information center, Moving into the Future. In this room, they completed a Self-Awareness Tool and a Transition Planner. These two transition tools were very help- 


\section{Figure 4}

Conceptual Framework for the StrategyTools Support System



Parents and Educators Supporting the Child

ful in two ways. First, they helped students recognize their strengths. This was important in developing their four-year plan in scheduling classes for their remaining years in high school. Second, they served to plan and provide documentation for the transitional component of their IEP meetings. The instructor noted that his students were more empowered to participate in their own IEPs because of tool usage.

The last room that the students utilized was the computer lab, Working on Projects. In this room, they worked together in a group using the Big Picture Card and Planning a Report tool to organize information and create a PowerPoint presentation for the incoming freshmen with disabilities on what to know about high school. With guidance from the teacher the students first brainstormed main idea topics for the "High School 411" project. Working as a group of four around one computer, the students entered the main ideas onto the Big Picture Card and generated supporting details and key points that they wanted to include in their presentation under each main topic. After printing out the tool and discussing the importance and appropriateness of each item with the teacher, the students revised their tool, adding details as necessary, and then printed it out to serve as an organizer for their PowerPoint presentation. 


\section{Table 2}

Listing of Tools in StrategyTools

\begin{tabular}{l|l|l|l|l|}
\multicolumn{1}{c}{$\begin{array}{c}\text { Participant/ } \\
\text { Ethnicity }\end{array}$} & \multicolumn{1}{c}{$\begin{array}{c}\text { Age/ } \\
\text { Grade }\end{array}$} \\
\hline $\begin{array}{l}\text { Donnie/ } \\
\text { Caucasian }\end{array}$ & $15 / 9^{\text {th }}$ & OHI/ADHD & $*$ SEE $80 \%$ & $\begin{array}{l}\text { Organization, accepting consequences, self-control (call } \\
\text { outs, loud “inside" voice) }\end{array}$ \\
\hline Mark/ Caucasian & $17 / 11^{\text {th }}$ & AU (Aspergers) & $*$ SEE $12.5 \%$ & $\begin{array}{l}\text { Social skills (interpreting social cues, developing social } \\
\text { relationships) }\end{array}$ \\
\hline Andy/ Caucasian & $15 / 9^{\text {th }}$ & BD & *SEE $100 \%$ & $\begin{array}{l}\text { Anger management, organization, social relationships } \\
\text { with peers }\end{array}$ \\
\hline $\begin{array}{l}\text { DeShane/ } \\
\text { African-American }\end{array}$ & $14 / 9^{\text {th }}$ & BD & $*$ SEE 100\% & $\begin{array}{l}\text { Using appropriate language, organization, task } \\
\text { completion }\end{array}$ \\
\hline
\end{tabular}

*SEE = Special Education Environment

The students then opened the Planning a Report tool. According to the teacher, this helped the students to think about the project and negotiate roles in the project with each team member. The completed tool also functioned as a written contract outlining how each student would participate. The students agreed to divide up the main ideas and take turns completing their slides in the PowerPoint presentation, and decided who was going to present each part. The students and teacher also decided what pictures they needed to illustrate their presentation and used a digital camera to capture these images to insert in the PowerPoint.

The students also used learning support tools to meet individual needs in classes outside the study skills class. These tools were based on assignments or personal difficulties with behavior and social skills in their classes. The teacher-researcher provided time for students to use these tools and offered explanations where needed. The additional tools, as shown on Table 1, helped students in the areas of learning, demonstrating learning, and solving personal problems.

Teacher monitoring and evaluation. The teacher varied his level of support and prompting depending on students' learning stage and individual needs. Initially, in order to support the use of the tools as the students first learned how to use them, the teacher took a few minutes at the beginning of each class to update and evaluate their Assignment Cards, To Do Lists, and Weekly Planners. Students could replace lost reports or create new ones at this time. The teacher made personal or email contacts with the students' general education teachers to let them know what tools/skills the students were using. For example, when the students began using the self-monitoring cards, the teacher asked the general education teachers to indicate on the cards their agreement/disagreement with the students' self-rating. As the students moved onto the Learning New Information and Demonstrating Learning tools, the teacher reduced the amount of support provided and had the students construct these tools independently. With a couple of students who worked on the Solving Problems cards, the teacher met individually with students and used the tools as a debriefing session for analyzing problems and developing better choices. After working together through these problems a couple of times, the student was encouraged to complete the tool independently when a problem arose.

\section{Data Collection and Analysis}

The teacher-researcher collected field notes to document students' implementation and comments about the tools and collected the tool reports that the students made during the semester. At the end of the semester, two researchers who were not involved in the classroom 
instruction conducted interviews individually with four students using a semi-structured interview protocol. Subsequently, they also held a focus group interview with the four students to discuss design and usability features of the software. In addition, the two participating teachers were interviewed using a semi-structured interview protocol-the teacher-researcher who implemented StrategyTools in his classroom and the first-year teacher who used the tools in her learning strategies class.

The student interviews were recorded and transcribed, and the transcripts were analyzed using qualitative research methods (Bogdan \& Biklen, 1998). Four sources-teacher interviews, student interviews, student artifacts, and a student focus group - were used to triangulate the data. Data were analyzed inductively, reflective of interpretivist research traditions (Lincoln \& Guba, 1985; Maxwell, 1996). All responses to each question were read and coded into common emergent themes. To establish interrater reliability, two of the researchers in this study independently coded each response into a theme or number of themes, then compared each response and corresponding theme category. Response codings that were not agreed upon were discussed and agreement was sought. Final interrater reliability on all questions was $100 \%$.

\section{Results}

\section{Student Comments on StrategyTools}

Positive impact. Students noted benefits in academic, behavior, and transition areas as a result of using the software. Two students indicated in their interview that the strategy tools they completed assisted them in recognizing and managing their behaviors. For example, one student noted that completing the problem-solving card served as an alternative behavior that replaced his more typical verbal or physical lashing out when another student made him angry. He spent a few minutes typing in the responses in the tool about what was bothering him and what he should do instead. When asked how it helped, he said, "after I calmed down and read everything I that wrote, [I] thought I made some pretty good decisions towards what I did." Another student noted that the tools helped him realize what he was doing that was getting him in trouble. He said, "like at the beginning of the year, I was respectful to teachers but if the teachers would yell at me for like no apparent reason, I'd just like flip out and like start backtalking them, and telling them to shut up and stuff but I don't do that any more." To the interviewer's follow-up question, "Have the tools helped?," the student responded, "Yeah, because I didn't really realize that I was doing it ... until I sat down and thought about it when we were doing this. And then I was like wow, I shouldn't be doing that."

This student particularly liked the self-recording aspect of the tool, noting, "if you're doing it for yourself, I mean that's building responsibility and that's building trust with other teachers that you can be responsible and you put down how you felt you acted instead of how they felt you acted."

With regard to transition planning, the tools facilitated more active engagement in the IEP process. One student said, "They were useful especially for my IEP. I typed out my career thing for it and then I printed it and I took it to my IEP and my mom read it and everything, so it was a help ... She [mom] thought that I did a good job of what I wanted to do for a career and how much I've already thought out about it."

Versatility. Students commented that the tools are useful for all students. One student commented, "I think all the students in schools could use them, not just in BD." Another student suggested they would be useful for any "people who like don't care about like their school work and stuff. Like, I think if they had this stuff, it would probably make them think about it more."

Concerns. Although the instructor felt that a Commitment Card was a good way for students to take responsibility for their behaviors and to decrease self-consciousness, the students indicated in their interviews that they were embarrassed about taking the card up to the teachers and wished that teachers could review student performance via email to prevent the student from being singled out. One student explained, "Well, if people saw it, they'll know like you're in like special classes and like special needs stuff. It sort of ruins your reputation of like how cool you are and everything and like if they see that you have a check sheet or something like that then they start picking on you and everything." In addition to these student concerns, the instructor noted that general education teachers were apprehensive about disagreeing with the students on their ratings. 
While they thought the tools would be useful in other classes and subjects, few students had taken advantage of them in situations other than those directed by their teachers. For example, students completed the To Do List and Weekly Planner cards as the first tools. Although all students had organizational goals on their IEPs, none of the four students interviewed mentioned the use or benefits of these tools in their interviews.

\section{Teacher Comments on StrategyTools}

Benefits. The two teachers viewed the design and usefulness of the tools positively. The experienced male instructor (teacher-researcher) said, "I think that the program lays out a lot of different strategies for kids to use. I will say that having it on a computer, kids love technology, you know, and it's bright and it's pretty and it has good graphics and the organization as far as looking down into the building, there are the different rooms and the different tools for each room. I think, you know, that's good. The layout of the different programs was really good ... very good for visual learners."

The first-year teacher talked about one of her students who used the Weekly Planner to help him meet his goal of being on the football team. She said, "So he set it out from 8:00 a.m. in the morning until 9:00 p.m. at night; what he wants to accomplish throughout that day and he writes it out a week ahead of time so then each day at the end of they day he can say, check I did this, check I went to weight lifting, yep I got my English homework done. You know he can do that and it's really made progress because he can see that goal." She commented further, "It really helps them. They can make the card. They can see their progress. They can see what they need help on. It's just a good program."

The instructor also reported that the students demonstrated pride in the cards they created, in particular the Moving into the Future cards. The students developed these cards in preparation for their IEP meetings and learned, through the tools, how to actively participate in their meetings. This activity helped them develop a sense of ownership in their IEP as manifested in confident participation by the students in the IEP meeting. The students' general education teachers reported that the To Do List had reduced the number of missing assignments and improved completion of late assignments. One stu- dent used tools in the Learning New Information room to complete a project on Israel that he put in the International Fair. His general education teachers and other adults in the building passed on their compliments about the student's project to the instructor.

Concerns. The first-year teacher indicated that the students had some difficulty working independently with the software and needed a lot of support from her to be able to use the tools. The experienced teacher commented that although the students liked the program, he had some concerns about student follow-through and subsequent impact of the program. "With behavior interventions, there was no follow through even with offering reinforcement-different types of reinforcement, having them choose their reinforcement. They still didn't follow through and I don't know whether that's due to our block scheduling where with an odd/even [schedule] I would see my kids every other day. I don't see them everyday and that makes it hard to check up their monitoring of their own behavior, to check up on their using the organizational tools." Other concerns related to the lack of computer access (only one computer in the room) and the fact that the students misplaced tool print-outs just as they had misplaced their planners.

\section{Discussion}

This qualitative study described the implementation of StrategyTools in a special education high school classroom and examined the students' and teachers' perceptions of the effectiveness and usability of the software. Both students and teachers reported that the software was well designed and the tools were well organized. Graphics and usability features were rated very high, with students identifying clearer benefits with regard to outcomes than teachers did. Students indicated that the tools had been useful in helping them to recognize triggers and their inappropriate responses as well as in identifying alternative, more appropriate responses. This suggests that EPSS may offer an effective way to provide training and assistance to students with EBD in acquiring and using self-regulation skills (Gustafson, 2000). It is also possible that this type of EPSS may serve as an assistive technology enabling students to acquire and practice the self-management and self-regulation skills that they need to participate successfully in general edu- 
cation settings. Clearly, much more research is needed in this area. As Fitzgerald (2005) noted, few studies have investigated the special education technology needs of students with emotional/behavioral disorders.

There were some limitations to this study. Interview data were collected from only two teachers and four students for one semester. It would be useful to collect more data, including observation data, on more students and teachers for a longer period of time. In addition, the study examined the use of only a selection of tools with a few students and did not investigate whether students continued to use these tools or explored the utility of additional tools in the absence of prompting by the teacher.

\section{Recommendations for Future Research}

As indicated above, future research should investigate the use of StrategyTools software with more students and teachers and assess variables affecting the effectiveness of implementation. In addition, data should be collected on multiple academic and behavioral outcomes as well as progress towards meeting IEP goals to determine the extent to which students benefit from the StrategyTools software. Finally, to examine the durability and sustainability of EPSS use, it would be useful to identify what levels of teacher and student supports are necessary to ensure use of the tools in non-training settings, and sustained use of the software and tools by teachers and students in the absence of researcher or teacher prompting. A current federally funded Steppingstones Technology of Innovation research project is underway using a randomized wait list control group design to investigate the issues identified above (Fitzgerald, Mitchem, \& Koury, 2006-2007). Twenty-four teachers and 96 students with disabilities across four school districts are participating in this study over the next three semesters (Fitzgerald et al., 2006-2007).

\section{Recommendations for Implementation}

Based on teacher and student feedback and comments, several recommendations and tips for using StrategyTools are noteworthy. First, when using StrategyTools in a setting with a limited number of computers, designate an area for students to access the computer, printer, and software and provide computer access time each day. Second, it is important to remember that the tools will not substitute for instruction in the strategies supported by the tools. Although it would be desirable to simply provide students with the software and have them independently learn to select, use, and apply the strategies across content areas, students with disabilities lack precisely these self-monitoring and self-regulation skills.

When using EPSS with students, teachers need to provide direct instruction and guided practice with the strategies, offer opportunities for the students to use these strategies for a variety of problems and contexts, and prompt the use of strategies to promote transfer. The tools can and do provide information and scaffolding to support subsequent use in a variety of settings; however, students must be introduced to the strategies and software and receive instruction in the strategies in a training setting. Materials are provided in the companion Strategy Coach website (http://strategytools.org) for students to work through six practice scenarios to select, make, and evaluate tools to solve the problem scenarios. Further, tips for successful tool usage are provided for all tools on this support web site. Once students have seen the potential of several tools, it is likely that they will begin to independently identify opportunities and select tools for use in untrained settings. The Strategy Coach web site provides interview excerpts from students in this study who implemented tool usage; these interviews may provide additional ideas to help motivate future students in using the tool approach.

Third, during implementation it is important to monitor and occasionally check students' self-monitoring. In addition, as a fourth recommendation, consider options for allowing students to submit their completed tools to and from teachers electronically to reduce potential embarrassment and to allow students to maintain "non-special ed" status in high school. Finally, teachers and parents must recognize that Strategy Tools is not enough by itself and is not a panacea. However, StrategyTools can be incorporated into a variety of school, home and community environments. Adults who assist students with tool usage should avail themselves of available system supports to develop the necessary background to the approach and the strategies by accessing the web-delivered training materials (http://kidtools.missouri.edu) and the information resource program (StrategyTools Resources).

Finally, it is recommended that StrategyTools be integrated in inclusive classroom settings across content areas. These tools support skills for all students; these are 
the skills that are needed for success in high school and beyond. All adults working with students across multiple settings need to embrace the underlying rationale of the approach to support students in taking responsibility for their own behavior, learning, problem solving, and futures planning. Full use of the system supports around StrategyTools will likely increase the effectiveness of the approach for students by supporting independent usage across training and generalization settings.

\section{References}

Anderson-Inman, L., \& Horney, M. (1997). Electronic books for secondary students. Journal of Adult and Adolescent Literacy, 40, 486-491.

Anderson-Inman, L., Knox-Quinn, C., \& Szymanski, M. (1999). Computer-supported studying: Stories of successful transition to postsecondary education. Career Development for Exceptional Individuals, 22, 185-212.

Biemiller, A., \& Meichenbaum, D. (1998). The consequences of negative scaffolding for students who learn slowly - A commentary on C. Addison Stone's "The Metaphor of Scaffolding": Its utility for the field of learning disabilities. Journal of Learning Disabilities, 31, 365-369.

Blackhurst, A. E. (1997). Perspectives on technology in special education. Teaching Exceptional Children, 29(5), 41-48.

Bogdan, R., \& Biklen, S. K. (1998). Qualitative research in education: An introduction to theory and methods ( $2^{\text {nd }}$ ed.). Boston: Allyn \& Bacon.

Brown, C., Hedberg, J., \& Harper, B. (1994). Metacognition as a basis for learning support software. Performance Improvement Quarterly, 7(2), 3-26.

Butler, D. (1995). Promoting strategic learning by postsecondary students with learning disabilities. Journal of Learning Disabilities, 28, 170-189.

Elam, S., Rose, L., \& Gallup, A. (1998). 28 ${ }^{\text {th }}$ annual Phi Delta Kappa/Gallup poll of the public's attitudes toward the public schools. Kappan, 80(1), 41-59.

Farrell, I., \& Moore, D. (2000). The effects of navigation tools on learner's achievement and attitude in a hypermedia environment. Journal of Educational Technology Systems, 29, 169-181.

Fitzgerald, G. (2005). Using technologies to meet the unique needs of students with emotional/behavioral disorders: Findings and directions. In D. Edyburn, K. Higgins, \& R. Boone (Eds.), The handbook of special education technology research and practice (pp. 335-354). Whitefish Bay, WI: Knowledge by Design.

Fitzgerald, G., \& Koury, K. (2001-2002). The KidTools support system (Project \#H327A000005). Washington, DC: United States Department of Education: Office of Special Education Programs.
Fitzgerald, G., \& Koury, K. (2004-2005). The strategy tools support system (Project \#H327A000005). Washington, DC: United States Department of Education, Office of Special Education Programs.

Fitzgerald, G., \& Koury, K. (2006). The effectiveness of technologyassisted instruction for students with mild/moderate disabilities. Unpublished manuscript, University of Missouri-Columbia.

Fitzgerald, Lynch, J., Semrau, L., \& Peng, H. (2000). User studies: Evaluating the use of EPSS tools for self-management by children. Proceedings of Ed-Media 2000 World Conference on Educational Multimedia and Hypermedia (pp. 1301-1303). Charlottesville, VA: AACE.

Fitzgerald, G., Mitchem, K., \& Koury, K. (2006-2007). Implementation of electronic performance support system (EPSS) tools for students with mild disabilities: Field-based research (Project \#H327A05066). Washington, DC: The United States Department of Education, Office of Special Education Programs.

Fitzgerald, G., \& Semrau, L. (1999). The development of KidTools. Journal of Special Education Technology, 15(3), 41-44.

Fitzgerald, G., \& Semrau, L. (1998). The effects of learner differences on usage patterns and learning outcomes with hypermedia case studies. Journal of Educational Multimedia and Hypermedia, 9, 309-331.

Fitzgerald, G., \& Werner, J. (1996). The use of the computer to support cognitive-behavioral interventions for students with behavioral disorders. Journal of Computing in Childhood, 7, 127-148.

Gery, G. (1991). Electronic performance support systems. Cambridge, MA: Ziff Institute.

Gustafson, K. (2000). Designing technology-based performance support. Educational Technology, 40, 38-44.

Hartley, K. (2001). Learning strategies and hypermedia instruction. Journal of Educational Multimedia and Hypermedia, 10(3), 285-395.

Individuals with Disabilities Education Act of 1990, PL 101-476. (October 30, 1990), Title 20, U.S.C. 1400 et seq.: U.S. Statutes at Large, 104, 1103-1151.

Individuals with Disabilities Education Improvement Act of 2004, Pub. No. 108-446, 118 Stat. 2647. (2004).

Kay, P. (1999). Prevention strategies that work: What administrators can do to promote positive student behavior. Burlington: University of Vermont.

Laffey, J. (1995). Dynamism in electronic performance support systems. Performance Improvement Quarterly, 8, 31-46.

Lewis, R. (2005). Classroom technology for students with learning disabilities. In D. Edyburn, K. Higgins, \& R. Boone (Eds.), The handbook of special education technology research and practice (pp. 325-334). Whitefish Bay, WI: Knowledge by Design.

Lewis, R., \& Doorlag, D. (2003). Teaching special students in general education classrooms (6th ed.). Upper Saddle River, NJ: Merrill/ Prentice Hall.

Lincoln, Y. S., \& Guba, E. G. (1985). Naturalistic inquiry. Beverly Hills, CA: Sage. 
Luca, J., \& Oliver, R. (2001). Developing generic skills through online courses. Proceedings of Ed-Media 2001 World Conference on Educational Multimedia and Hypermedia. Charlottesville, VA: AACE.

Maxwell, J. A. (1996). Qualitative research design: An interactive approach. Thousand Oaks, CA: Sage.

Miller, K. J., Koury, K., Mitchem, K., Fitzgerald, G., \& Hollinsead, C. (2005). Using electronic performance support systems for students in inclusive settings. Proceedings of the Inclusive \& Supportive Education Congress: An International Special Education Conference. Glasgow, Scotland.

Miller, K. J., Mitchem. K., Fitzgerald, G., Koury, K., \& Hollingsead, C. (2004). KidTools/KidSkills: Self-management, problem solving, organizational and planning tools for children. Proceedings of the American Council on Rural Special Education, 6-8.

No Child Left Behind Act of 2001, Pub. L. No.107-110, 115 Stat.1425. (2001).

Peled, Z., Peled, E., \& Alexander, G. (1994). An ecological approach for information technology: Intervention, evaluation, and software with learning disabilities: The present, the prospects, the pitfalls. Journal of Learning Disabilities, 29, 317-324.

Reid, R. (1996). Research in self-monitoring with students with learning disabilities: The present, the prospects, the pitfalls. Journal of Learning Disabilities, 29(3), 89-103.

Schaff, J., Bannan-Ritland, B., Behrmann, M., \& Ok, S. (2005). Electronic performance support systems. In D. Edyburn, K. Higgins, \& R. Boone (Eds.), Handbook of special education technology research and practice (pp. 493-506). Whitefish Bay, WI: Knowledge by Design.

Swanson, H. (1988). Toward a metatheory of learning disabilities. Journal of Learning Disabilities, 21, 196-209.
Swanson, H., \& Hoskyn, M. (1998). Experimental intervention research on students with learning disabilities: A meta-analysis of treatment outcomes. Review of Educational Research, 68, $277-321$.

U.S. Department of Education. (2004). To assure the free appropriate public education of all children with disabilities: Twenty-sixth annual report to Congress on the implementation of The Individuals with Disabilities Education Act. Washington, DC: U.S. Government Printing Office.

Woodward, J., \& Rieth, H. (1997). A historical review of technology research in special education. Review of Educational Research, 67, 503-556.

\section{Author Notes}

Dr. Katherine Mitchem is an Associate Professor and Graduate Coordinator in the Special Education Department, California University of Pennsylvania. Jason Kight is a high school teacher and Instructor in the Special Education Department, California University of Pennsylvania. Dr. Gail Fitzgerald is a Professor in the School of Information Science \& Learning Technologies at the University of Missouri-Columbia. Dr. Kevin Koury is the Berger Endowed Chair, Professor and Chair of the Special Education Department, California University of Pennsylvania. Thitinun Boonseng is a doctoral candidate in the School of Information Science of Learning Technologies at the University of Missouri-Columbia.

Correspondence should be addressed to Katherine Mitchem, 210 Keystone Hall, 250 University Avenue, California, PA, 15419. Email to mitchem_k@cup.edu 